Georgia State University

ScholarWorks @ Georgia State University

\title{
Neurocognitive Predictors of Reading Outcomes for Children With Reading Disabilities
}

\author{
Jan Frijters \\ Brock University, jan.frijters@brocku.ca \\ Maureen Lovett \\ University of Toronto, mwl@sickkids.ca \\ Karen Steinbach \\ University of Toronto, Karen.steinbach@sickkids.ca \\ Maryanne Wolf \\ Tufts University, maryanne.wolf@tufts.edu \\ Rose Sevcik \\ Georgia State University, rsevcik@gsu.edu
}

See next page for additional authors

Follow this and additional works at: https://scholarworks.gsu.edu/psych_facpub

Part of the Psychology Commons

\section{Recommended Citation}

Frijters, J.C., Lovett, M.W., Steinbach, K.A., Wolf, M., Sevick, R.A. \& Morris, R. (2011). Neurocognitive predictors of reading outcomes for children with reading disabilities. Journal of Learning Disabilities, 44(2), 150-166.

This Article is brought to you for free and open access by the Department of Psychology at ScholarWorks @ Georgia State University. It has been accepted for inclusion in Psychology Faculty Publications by an authorized administrator of ScholarWorks @ Georgia State University. For more information, please contact scholarworks@gsu.edu. 


\section{Authors}

Jan Frijters, Maureen Lovett, Karen Steinbach, Maryanne Wolf, Rose Sevcik, and Robin D. Morris 


\title{
Neurocognitive Predictors of Reading Outcomes for Children With Reading Disabilities
}

\section{Jan C. Frijters ${ }^{1}$, Maureen W. Lovett ${ }^{2}$, Karen A. Steinbach ${ }^{2}$, Maryanne Wolf ${ }^{3}$, Rose A. Sevcik ${ }^{4}$, and Robin D. Morris ${ }^{4}$}

\author{
${ }^{1}$ Brock University, St. Catharines, Ontario, Canada \\ ${ }^{2}$ The Hospital for Sick Children, Toronto, Ontario, Canada \\ ${ }^{3}$ Tufts University, Boston, MA, USA \\ ${ }^{4}$ Georgia State University, Atlanta, USA \\ Corresponding Author: \\ Jan C. Frijters, Brock University, Departments of Child and Youth Studies and Psychology, 500 Glenridge Ave., St. Catharines, Ontario, L2S 3A1, \\ Canada \\ Email: jan.frijters@brocku.ca
}

\begin{abstract}
Abstret
This study reports on several specific neurocognitive process predictors of reading outcomes for a sample of 278 children with reading disabilities. Three categories of response (i.e., poor, average, and good) were formed via growth curve models of six reading outcomes. Two nested discriminant function analyses were conducted to evaluate the predictive capability of the following models: (a) an intervention and phonological processing model that included intervention group, phonological awareness, and rapid naming and (b) an additive cognitive neuropsychological model that included measures of memory, visual processes, and cognitive or intellectual functioning. Over and above the substantial explanatory power of the base model, the additive model improved classification of poor and good responders. Several of the cognitive and neuropsychological variables predicted degree of reading outcomes, even after controlling for type of intervention, phonological awareness, and rapid naming.
\end{abstract}

\section{Keywords}

treatment, dyslexia, response to intervention, reading, neuropsychological assessment

Two specific language processes have been consistently and convincingly demonstrated to be a key-and some would say a causal-skill set underlying the successful development of reading skill. These processes are phonological awareness (PA), or the manipulation of individual sounds in the speech stream (Liberman \& Shankweiler, 1985; Wagner \& Torgesen, 1987), and rapid automatized naming (RAN), or the rapid naming of serial displays of visual symbols such as letters, numbers, objects, and colors (Wolf \& Bowers, 1999; Wolf, Bowers, \& Biddle, 2000). A comprehensive meta-analysis of correlational research linking these processes and reading achievement is provided by Swanson, Trainin, Necoechea, and Hammill (2003).

Deficiencies in PA and naming speed have been demon- strated to be characteristic of individuals with reading dis- abilities (RD) and those who struggle to acquire basic reading skills. Past research has shown that PA and RAN are distinct constructs but related in their prediction of read-ing processes. Providing independent predictive power to explaining reading skills, deficits in both PA and

RAN prior to being able to read have been related to Grade 2 and Grade 3 reading ability (Manis, 
Seidenberg, \& Doi, 1999; Wimmer, Mayringer, \& Landerl, 1998). The two skills may also have a different developmental course, with PA exerting more influence on early, decoding-dependent tasks and RAN exerting more influence on later, word identification and fluency-dependent tasks (Kirby, Parrila, \& Pfeiffer, 2003; Wolf et al., 2002).

Several authors have suggested recently, in reviews and in meta-analyses, that a great deal is known about what con- stitutes efficacious intervention for reading problems (for comprehensive reviews, see Block, Parris, Reed, Whiteley, \& Cleveland, 2009; Lovett, Barron, \& Benson, 2003; Lovett et al., 2005; Torgesen, 2005). Despite what is understood about the process of typical reading development and about what constitutes effective intervention for reading acquisition failure, the processes that moderate intervention response for particular individuals with RD may be quite different. Far less is known of this aspect of intervention for RD.

Two reviews have synthesized a small but growing literature on the factors that predict degree of response to reading intervention. Al Otaiba and Fuchs (2002) focused on young children at risk for RD and reviewed studies in which the characteristics of children unresponsive to intervention were investigated. Nelson, Benner, and Gonzalez (2003) reviewed many of the same studies, but in a quantitative meta-analytic framework and with a broader focus on intervention efficacy. Across both reviews, PA and rapid naming were consistently associated with the degree of intervention response. Al Otaiba and Fuchs reported that poor PA predicted nonresponse in 16 of the 21 studies that included this construct; similarly, slow naming speed predicted nonresponse in five of six studies that measured this construct. Nelson et al. reported in their analyses that the mean effect sizes for the prediction of intervention efficacy from PA (0.42) and rapid naming (0.51) were equivalent. In addition, these two skills yielded the strongest effect sizes, substantially higher than effects for behavior, orthography, memory, and IQ.

Notably absent, or consistently associated with smaller effect sizes in the studies covered by these reviews, are several specific neurocognitive processes. Of the 23 studies reviewed by Al Otaiba and Fuchs (2002), 7 included memory measures and 15 included some measure of IQ. In both cases, there were equivocal results for each construct, with some studies reporting associations with nonresponse and some studies reporting none. Within the studies reviewed by Nelson et al. (2003), effect sizes for memory $(M=0.30)$ and IQ $(M=0.26)$ were substantially smaller than those for the phonologically based constructs, which consistently demonstrated stronger evidence of association with reading. Recent studies have tested IQ as a moderator effect but have not found evidence of differential growth or change along these dimensions. For example, Lovett et al. (2008) and Morris et al. (2010) compared growth curves for aver- age versus low IQ participants and found parallel treatment curves within intervention conditions. Fuchs and Young (2006) have recently shown mixed and small effects for IQ as a predictor of intervention responsiveness, especially for younger children and for word identification outcomes.

There may be several reasons for these patterns of findings. The first is that such factors as IQ are not important to remedial outcome-that current best practice multiple component interventions are largely "complete instruction." That is, individual differences in skills and knowledge are compensated for through interventions designed to provide explicit instruction, repeated practice, and structured attention to facilitating generalization of learning (Braden \& Shaw, 2009). However, were this the case, studies of sufficient power should show moderation effects for IQ, with steeper growth rates or greater gains for children low on IQ and related factors. Another possibility in the case of IQ may be that the measure of IQ predominately analyzed in studies to date has been the full-scale IQ measure, obscuring and even averaging out critical profile differences that may predict responsiveness (Fiorello, Hale, \& Snyder, 2006). Finally, Fuchs and Young (2006) have demonstrated in their review of 13 studies that the contribution of IQ to explaining responsiveness systematically depends on the type of instruction (i.e., a stronger relationship when the instruction is comprehensive), outcome 
measure (i.e., a stronger relationship when the outcomes are not single word identification or nonword reading but more complex reading tasks), and age of the children involved (i.e., a stronger relationship for children beyond Grade 2). As is argued below, several cognitive and neuropsychological constructs have a rich theoretical history, and at least some have demonstrated empirical evidence of association with reading processes-if not as moderators of intervention outcome. Many cognitive and neuropsychological constructs may have not been studied as predictors of responsiveness sim- ply because of the focus on the reading-related language processing factors studied most to date, PA and rapid naming.

\section{Phonological Coding}

The process of encoding or representing linguistic information for later analysis and synthesis is a cognitive skill that underlies PA, grapheme-phoneme mapping, and the development of individual word identification. These processes have been studied at several levels of resolution, including the individual phoneme and the morpheme. There is strong evidence that these processes underlie vocabulary development (Gathercole \& Baddeley, 1990; Metsala, Stavrinos, \& Walley, 2009) and spoken language comprehension (Baddeley, 1986). Scarborough (1998) showed that verbal memory measured in second grade substantially predicted reading achievement in eighth grade, but only for normally developing readers. Gathercole, Alloway, Willis, and Adams (2005) reported that phonological memory at the phoneme and word levels was a significant predictor of reading for children with RD, though weaker in predictive power than complex working memory tasks. One form of phonological coding is nonword repetition, and its relationship with reading on theoretical and empirical levels has been systematically reviewed by Gathercole (2006). The key dynamic in this relationship is that the ability to repeat nonwords is an index of the overall quality of the phonological storage system, involved in vocabulary, word learning, and PA.

A recent meta-analysis synthesized the literature com- paring children with and without RD on measures of working memory and short-term memory (Swanson, Zheng, \& Jerman, 2009). This review included 43 studies between 1963 and 2006 that involved verbal short-term memory comparisons of these groups of children. Across these studies, phonological memory measured in tasks such as nonword repetition was significantly impaired for children with RD when compared to agematched children (weighted effect size $=-0.39$ ). The parallel effect size for word-level short- term memory was -0.55. In the fully partial model that con- trolled for the influence of working memory and attention, only phonological memory among measures of short-term memory was retained as significantly impaired in the group with RD. Berninger, Raskind, Richards, Abbott, and Stock (2008) reviewed evidence that children with RD with the chromosome 6 DCDC2 deletion allele differ from children without RD on phonological short-term memory, specifically on tasks of nonword repetition. In addition, they reviewed evidence that children with $\mathrm{RD}$ with a transcription site alteration in $\mathrm{DYX} 1 \mathrm{C} 1$ also differed from children without RD. Thus, phonological coding appears to be consistently impaired among children with RD, with stronger evidence for impairment at the level of individual phonemes than at the word level.

However, whether phonological coding is related to change in reading skill is an open question. When readers with RD were compared to skilled readers and to a combined RD and calculationdisordered group, Swanson and Jerman (2007) found that nonword repetition and word- level shortterm memory did not predict rates of growth in reading ability. However, Berninger et al. (2008) also reviewed evidence that differences with and without $\mathrm{RD}$ in the left inferior frontal and parietal regions are evident before but not after PA training, suggesting that changes in phonological coding may occur in conjunction with the reading growth associated with intervention. 


\section{Visual Processes}

Visual-motor integration (VMI) is the process of integrating visual perception with body movements. Although the act of reading does not require motor output per se, there is empirical evidence of a relationship between reading skill and VMI. Across 161 studies, VMI was shown to have consistently moderate relationships with reading processes, with stronger relationships for word reading versus other reading outcomes and for younger children versus older children (Kavale, 1982; median $\mathrm{r}=$ .39). Younger children were identified as "preschool" and older as "intermediate," with an average age of 7.88 years and an average grade of 3.2 in this review. However, in another review covering more recent studies, smaller relationships with reading achievement were found (Scarborough, 1998; median $\mathrm{r}=.28$ ). This latter finding was confirmed in a recent multivariate dominance analysis (Schatschneider, Fletcher, Francis, Carlson, \& Foorman, 2004) that yielded correlations ranging from .21 to .29 depending on the particular reading outcome studied and whether VMI was assessed in April or October of the kindergarten year. Notably, the earlier studies reviewed in the meta-analyses focused on cross-sectional relationships with reading skill, whereas the Schatschneider et al. (2004) study specifically investigated kindergarten predictors of Grade 1 and 2 reading outcomes. O'Malley, Francis, Foorman, Fletcher, and Swank (2002) found that children without reading impairment in kindergarten and Grade 1 showed more robust growth from initial assessment to Grade 2 in the development of VMI itself.

There has been some debate about the nature and contribution of visual sequential memory (VSM) to explaining variability in reading skill (see Scheiman \& Rouse, 2005). In a longitudinal study of the kindergarten cognitive predictors of Grade 4 reading, Grogan (1995) found a moderate contribution of VSM to reading skill (i.e., $\Delta \mathrm{R} 2=.05$, after accounting for age, auditory memory, and motor skills). Kavale's (1982) earlier meta-analysis showed substantial associations between VSM and word reading ( $\mathrm{rs}=.40$ to .49), with stronger relationships found for the younger children. Differences on tasks of VSM have been found when the performances of normally developing and children with RD (Watson \& Willows, 1995) have been compared. Differences in VSM were substantial when children with RD were matched with younger successful readers, a reading- level match that controlled for reading experience. There is also evidence contextualizing these findings that children with RD do not have visual memory problems per se but are less likely to adopt a verbal labeling strategy on such tasks. For example, children with RD can improve VSM with training (Hicks, 1980). In addition, given the substantial contribution of naming speed to reading skill, the rate of visual stimuli presentation can have a marked impact on whether relationships with reading skill are found (Huba, Vellutino, \& Scanlon, 1990). Thus, the deficiencies in VSM that have been observed may be the result of verbal or rate issues and not VSM per se.

\section{Intelligence Quotient}

Across several studies and meta-analyses, no systematic differences in the reading achievement of children with RD or LD that are attributable to IQ have been shown to exist (Fletcher et al., 2002; Gustafson \& Samuelsson, 1999; Hoskyn \& Swanson, 2000; Siegel, 1989, 1992; Stanovich \& Siegel, 1994; Stuebing et al., 2002). The vast majority of previous studies have examined global intelligence for potential direct relationships to reading achievement. More recently, perhaps because of reduced interest in IQ discrepancy versus low achievement definitional debates (see Fletcher et al., 1994; Scruggs \& Mastropieri, 2003), more nuanced investigations into the role of intelligence have emerged. Tiu, Thompson, and Lewis (2003) tested a structural model of reading across normally developing and samples with RD and found that performance IQ (PIQ) was related to reading comprehension, but only for children with RD and only as mediated by decoding skill. Consistent with these results, Johnston and Morrison (2007) recently matched poor readers, reading age controls, and chronological age controls and divided them into high $(>101)$ and low $(<100)$ IQ subsamples to form six comparison groups. Their results showed that IQ moderated the relationship between reading outcome and specific phonological deficits, such that high IQ poor readers manifested more severe phonological reading deficits. 
Another way in which the IQ-reading relationship has been obscured is that many studies have not considered the well-defined factors that constitute global intelligence scores. Vellutino, Scanlon, and Lyon (2000) reported correlations between reading achievement and Verbal and PIQ factors at several points from Grade 1 through Grade 4. Their results indicated that verbal IQ (VIQ) was correlated with word identification for normal readers from Grade 2 onward, but for difficult to remediate readers the correlation that was apparent in Grade 1 was nonsignificant by the winter of Grade 2. In a recent confirmatory factor analysis of the Wechsler Intelligence Scale for Children-Fourth Edition (WISCIV), Glutting, Watkins, Konold, and McDermott (2006) found that reading achievement on the Wechsler Individual Achievement Test was related to a $g$ factor but that the verbal comprehension index also had a direct relationship with reading skill. In an earlier confirmatory factor analysis of the WISC-III, Oh, Glutting, Watkins, Youngstrom, and McDermott (2004) found a similar pattern of relation- ships, with an additional negative relationship between the perceptual organization factor and reading processes. Hale, Fiorello, Kavanagh, Holdnack, and Aloe (2007) have noted that using $g$ alone, or together with subcomponent scores, is problematic because of the inherent multicollinearity between full-scale IQ and these components derived from it. It is important to contextualize the WISC-IV studies with reference to other studies that have examined the relationship of Cattell-Horn-Carroll factors with reading (e.g., Evans, Floyd, McGrew, \& Leforgee (2001)). These studies have demonstrated that a focus on $g$ incurs a loss of profile information that is contained within subcomponents (Hale et al., 2007). Floyd, Keith, Taub, and McGrew (2007, for example, found persistent indirect relationships between $g$ and decoding, whereas within a two stratum structural model processing speed and crystallized intelligence (i.e., specifically listening ability within a four stratum model) had direct relationships with reading (see also Evans et al., 2001).

There exists enough research and knowledge about the development of reading processes to suggest that short-term memory, visual memory, and IQ are important factors. Little research is available to suggest whether any of these factors moderate degree of response to reading intervention among struggling readers. The present study investigates the contribution of eight specific neurocognitive process predictors to understanding degree of intervention response among young children with RD. Each of these predictors has a theoretical or, at minimum, an empirical association with reading skill. After estimating intervention response via multilevel human growth curve models, three categories of response were formed. Through a discriminant function analysis of these categories the following research questions were considered:

1. What is the contribution of intervention condition, PA, and RAN to explaining degree of intervention response, as measured by individual growth curves?

2. Beyond the contribution of specific intervention conditions, PA, and RAN skills, do specific neurocognitive processes make independent contributions to knowing which children with RD show a poor, average, or good reading outcome?

3. Does the inclusion of specific neurocognitive process measures improve the ability to classify intervention participants into poor, average, and good responders; more specifically, for which category does it improve classification the most?

\section{Method}

\section{Participants}

The current study reports on 278 participants originally reported in Morris et al. (in press). Each child participated in a multisite intervention study that compared four small- group interventions (described below) that provided 70 hours of intensive instruction. Children between 78 and 102 months whose first language was English were recruited through referrals from classroom teachers who considered them to have significant difficulty acquiring reading skills. Referral was followed by administration of a screening battery consisting of the Kaufman Brief Intelligence Test (K-BIT; Kaufman \& Kaufman, 1990), the Woodcock Reading Mastery Tests-Revised (WRMT-R; Woodcock, 1987), the Wide Range 
Achievement Test-3rd Edition (WRAT-3; Wilkinson, 1993), and a demographic questionnaire completed by parents. The screening battery was administered by trained psychometrists at each of three sites (Atlanta, Georgia; Boston, Massachusetts; Toronto, Ontario).

Two criteria were used to determine whether the child had a RD. The low achievement criterion was met with a K-BIT Composite standard score greater than or equal to 70 and a standard score of 85 or lower on at least one of three reading indices as follows: (a) the average of the WRAT- 3 Reading subtest, the WRMT-R Word Identification, Word Attack, and Passage Comprehension subtests; (b) the WRMT-R Basic Skills Cluster Score; (c) the WRMT-R Total Short Scale Score. The ability-achievement regression- corrected discrepancy criterion was met with a reading index one standard error of the estimate below the regression- predicted reading score. An assumption of an average .6o correlation between the reading indices described above and the K-BIT Composite Index was used to calculate the discrepancy scores. A child qualified for inclusion having met either or both criteria.

\begin{tabular}{|c|c|c|}
\hline & M & $S D$ \\
\hline Age at intervention start (months) & 93.59 & 6.07 \\
\hline WRMT-R Word Attack (SS) & 76.57 & 11.94 \\
\hline WRMT-R Word Identification (SS) & 73.38 & 10.39 \\
\hline WRMT-R Passage Comprehension (SS) & 78.49 & 9.85 \\
\hline K-BIT Matrices (SS) & 91.54 & 11.16 \\
\hline K-BIT Vocabulary (SS) & 94.12 & 10.61 \\
\hline K-BIT Composite (SS) & 90.60 & 13.46 \\
\hline$\%$ male & \multicolumn{2}{|c|}{61.5} \\
\hline $\begin{array}{l}\% \text { below I SD age expectations on } \\
\text { WRMT-RWord Identification }\end{array}$ & \multicolumn{2}{|c|}{75.8} \\
\hline $\begin{array}{l}\% \text { below I SD age expectations on } \\
\text { WRMT-R Passage Comprehension }\end{array}$ & \multicolumn{2}{|c|}{77.3} \\
\hline $\begin{array}{l}\text { \% below I SD age expectations on } \\
\text { Word Reading Efficiency }\end{array}$ & \multicolumn{2}{|c|}{94.6} \\
\hline
\end{tabular}

Note: WRMT-R - Woodcock Reading Mastery Tests-Revised;

SS -Standard Score; K-BIT - Kaufman Brief Intellgence Test.

Morris et al. (in press) described in more detail the number of children screened and the procedures for defining RD status and ensuring representative sampling of socio- economic levels, IQ, and race. The sampling strategy resulted in equal numbers and at least 8 children per cell, with at least 64 per condition and no site contributing more than 5 participants in any cell. The specific levels of the three factors were as follows: socioeconomic level, derived from demographic information provided by parents, as low or average and above; IQ as low (70-90) or average and above (>90); race as reported by the participants' parents, either Black or Caucasian. Table 1 details the average read- ing ability, IQ, and age of the 278 children participating in the present study. Males constituted $61.5 \%$ of the sample. Also contained in Table 1 is the proportion below $1 S D$ age- expected performance across the following individual measures: word reading (WRMT-R Word Identification), comprehension (WRMT-R Passage Comprehension), and fluency (Word Reading Efficiency). After confirmation of RD, the WISC-III (Wechsler, 1991) was administered to all children along with the cognitive and neuropsychological measures detailed below.

The study design involved random assignment of small groups of struggling readers, and their intervention teachers, to one of four remediation conditions. The factorial design of the study developed four randomly assigned groups of struggling readers, such that each group included equal numbers of Caucasian and Black students, of students with average and below average family socioeconomic situations, and of students with average and below average IQ. Groups of four children from each 
sample were taught one of four remedial programs (detailed below) by trained teachers for 70 contact hours during the school year.

\section{Remedial Intervention Programs}

Participants with similar single word reading levels (WRMT-R and WRAT-3 Reading raw scores) were assigned to an instructional group of four children, and these groups were randomly assigned to one of four intervention programs. Children were taught by trained teachers in a pull-out format for 60 minutes a day, four to five days a week, for a total of 70 intervention sessions. The intervention design included five components (Phonological Analysis and Blending/Direct Instruction-PHAB/DI, Word Instruction Strategy Training-WIST, Retrieval, Automaticity, Vocabulary Elaboration, OrthographyRAVE-O, Classroom Survival Skills-CSS, Mathematics Program-MATH) that were combined, two at a time, into four different intervention programs. The PHAB/DI component (a phonological decoding program based on Reading Mastery Fast Cycle I/II by Engelmann \& Bruner, 1988), part of each reading intervention, averaged 30 minutes of instructional time in every lesson.

The four programs resulting from combinations of these components were the Phonological and Strategy Training Program (PHAST), PHAB+RAVE-O, PHAB+CSS, and MATH+CSS. The first two were new experimental, multiple component interventions (PHAB/DI+WIST, which became PHAST, and PHAB/DI+RAVE-O). PHAST (Lovett, Lacerenza, \& Borden, 2000; Lovett et al., 2005) and the RAVE-O program (Wolf et al., 2009; Wolf, Miller, \& Donnelly, 2000) have been described in detail in separate publications. PHAST integrates direct instruction of letter- sound mapping and phonological decoding with increasingly autonomous word identification strategy training. This integration is illustrated in the sequence of five strategies introduced in a skill-based sequence as follows: (a) "Sounding Out," (b) "Rhyming," (c) "Peeling Off," (d) "Vowel Alert,” (e) "I Spy.” A scaffolded framework of instruction incorporates explicit training in strategy selection, application, and monitoring as guided by the metacognitive "Game Plan." The three core goals of RAVE-O are developing internal word structure pattern analysis at the phonological and orthographic level, building word retrieval capacity through strategies and vocabulary development, and engaging in semantic analysis of words for their roots and meaning associations. One core component of the pro- gram, vocabulary elaboration, emphasizes the following through games and activities in group and on the computer: (a) the multiplicity of meanings in each word (e.g., flexibility in word use), (b) semantic breadth (e.g., associations of word), (c) semantic depth (e.g., contexts and use of word), and (d) morphological endings (e.g., "Ender Benders"). Each of these two intervention combinations devoted equal time to its two components. The remaining two programs served as control or contrast conditions: MATH $+\mathrm{CSS}$ served as an alternative treatment control condition, and PHAB/DI+CSS provided a phonological-only reading comparison.

\section{Outcome Measures}

Six reading and reading-related outcome measures were included in the present study. These ranged from one phonological skill outcome to several measures of single word identification, including a speeded measure, and one mea- sure of passage comprehension. The measures for the present analysis were chosen from a much larger set of outcomes assessed with this sample; the present subset of outcome measures was selected to include four standardized measures and provide a broad assessment of reading ability. Outcomes were assessed before intervention began, after 35 hours of intervention, and again after 70 hours of intervention. An overview of each outcome, the construct it measures, and basic reliability and validity information are provided below, but see Morris et al. (in press) for more details on all aspects of the measures, the interventions, and the overall study design.

Research-based measures. Blending Words from the Comprehensive Tests of Reading Related Phonological Processing (CTRRPP; Torgesen \& Wagner, 1996 was the research version of the test in current publication - the Comprehensive Tests of Phonological Processing (CTOPP; Wagner, Torgesen, \& Rashotte, 1999). This subtest assessed the ability to combine individual orally presented phonemes into real words. For the age range in the present study, the measure's authors report the internal 
consistency reliability (coefficient alpha) to be .92 for a sample of normally developing readers and .87 for a sample of 61 children with RD. Test-retest reliability for this age range was .88.

The Test of Transfer is a computer-administered, timed word identification test consisting of 40 words that are systematic transformations of high-frequency spelling patterns taught in the intervention programs (Lovett et al., 2000). For example, the keyword bake is taught in the intervention, and the Test of Transfer may contain fake, babe, bike, and baker. These four words represent onset, rhyme, vowel, and suffix-based transformations of the keyword. Words were presented singly and displayed on a computer monitor for 6,000 milliseconds, and children responded orally, speaking into a microphone to trigger the next list word. Cirino et al. (2002) report the test-retest reliability of this measure to be .94 for the present sample. Raw scores of both Blending Words and the Test of Transfer were used in the present analysis.

Standardized tests of reading processes. Three subtests from the WRMT-R, Form G (Woodcock, 1987) were administered. The Word Identification, Word Attack, and Passage Comprehension subtests represent respectively context-free assessments of single-word reading, nonword decoding, and reading comprehension assessed through a cloze procedure.

Internal consistency reliability derived from the normative sample for these subtests was .98, .94, and .98, respectively. A measure of word-level fluency, the Word Reading Efficiency test, was also administered (Torgesen \& Wagner, 1996). This test is the research version of the currently published Test of Word Reading Efficiency (TOWRE) Sight Word Reading subtest (Torgesen et al., 2001), and the items overlap substantially with this test and partially with the WRMT-R Word Identification subtest. Children are asked to read as many words as quickly and accurately as possible from a list of 104 real words. The raw number of words read within 45 seconds represented a measure of single-word reading fluency. Test-retest reliability for children in the same age range as the present sample ranged from .93 to .97 . Test-retest reliability for 29 children with RD ages 6 to 9 was .97 .

\section{Neurocognitive Process Predictors}

Predictors included in the present study were drawn from a broad range of cognitive and neuropsychological predictors originally assessed within the present sample. Selection of predictors was guided by demonstrated theoretical or empirical links with either reading processes or with response to remediation, as reviewed earlier. In total eight specific neurocognitive process measures were included, along with two oral language skills.

Oral language skills. The Elision subtest from the CTRRPP and the Letters array from the Rapid Automatized Naming task (Denckla \& Rudel, 1974, 1976) were chosen for inclusion in the base model described below. These two particular measures were chosen because of the strong history of empirical association with both reading skills and remedial response. The Elision subtest is a phonological analysis task that requires children to orally segment individual phonemes from within words and resynthesize them. The Rapid Automatized Naming Letters task presents five letters, randomly arrayed in 5 lines of 10 items. Children are required to rap-idly name the letters, and time to complete the full array is the score for this measure.

Memory processes. The CTRRPP subtests Memory for Words and Nonword Repetition are measures of phonologically mediated short-term memory, at two levels of resolution. The Nonword Repetition task requires children to repeat a graduated series of 25 nonwords increasing in the number of phonemes, presented orally in succession via a prerecorded audiotape. This task is discontinued after five consecutive errors. The Memory for Words task requires children to listen to and then repeat orally a word sequence. Words are presented with increasing list length, until three consecutive errors are made.

Visual processes. The Beery-Buktenica Developmental Test of Visual-Motor Integration, $5^{\text {th }}$ Edition (VMI; Beery, \& Buktenica, 1989) is a structured measure of visual-motor 
Table 2. Growth Curve Models of Outcome Variables

\begin{tabular}{|c|c|c|c|c|c|c|c|c|c|c|c|c|c|c|}
\hline \multirow[b]{2}{*}{ Fixed Effects } & & \multirow[b]{2}{*}{ Par. } & \multicolumn{2}{|c|}{$\begin{array}{l}\text { CTRRPP } \\
\text { Blending }\end{array}$} & \multicolumn{2}{|c|}{$\begin{array}{l}\text { WRMT-R Word } \\
\text { Att. }\end{array}$} & \multicolumn{2}{|c|}{$\begin{array}{l}\text { Test of } \\
\text { Transfer }\end{array}$} & \multicolumn{2}{|c|}{$\begin{array}{l}\text { WRMT-R Word } \\
\text { Id. }\end{array}$} & \multicolumn{2}{|c|}{$\begin{array}{l}\text { WRMT-R P. } \\
\text { Comp. }\end{array}$} & \multicolumn{2}{|c|}{$\begin{array}{l}\text { TOWRE S. } \\
\text { Word }\end{array}$} \\
\hline & & & Par. & SE & Par. & SE & Par. & SE & Par. & SE & Par. & SE & Par. & SE \\
\hline Initial status & Intercept & $\gamma_{\infty}$ & $9.76^{* * *}$ & 0.27 & $448.62^{* * 8}$ & 0.77 & $3.76 \%$ & 0.39 & $402.84^{* k *}$ & 1.54 & $439.92^{* *}$ & 1.02 & $12.25^{* *}$ & 0.57 \\
\hline Rate of change & Intercept & $\gamma_{10}$ & $2.19 * k$ & 0.12 & $10.06^{* * *}$ & 0.40 & $4.64^{* * *}$ & 0.25 & $14.83^{* *}$ & 0.47 & $9.30^{k-k}$ & 0.40 & $5.01^{* *}$ & 0.19 \\
\hline \multicolumn{15}{|l|}{$\begin{array}{l}\text { Variance } \\
\text { components }\end{array}$} \\
\hline Level I & $\begin{array}{l}\text { Within } \\
\text { person }\end{array}$ & $\sigma^{2}$ & $4.14^{1 * k}$ & 0.35 & $69.24 \%$ & 5.90 & $10.13^{* *}$ & 0.88 & $39.63^{* * *}$ & 3.37 & $49.14^{* * *}$ & 4.18 & $6.06 * *$ & 0.51 \\
\hline \multirow[t]{2}{*}{ Level 2} & $\begin{array}{c}\text { In initial } \\
\text { status }\end{array}$ & $\sigma_{0}^{2}$ & $16.84^{\text {k1k }}$ & 1.75 & $105.53^{* * *}$ & 14.73 & $32.82 \%$ & 3.61 & $622.51^{\text {*** }}$ & 55.79 & $249.40^{\text {k* }}$ & 24.95 & $83.97^{* * *}$ & 7.58 \\
\hline & $\begin{array}{l}\text { In rate of } \\
\text { change }\end{array}$ & $\sigma^{2}$ & $1.91 * *$ & 0.38 & $10.23 *$ & 4.82 & $11.80^{* * *}$ & 1.50 & $42.32^{* k}$ & 5.55 & $20.38^{k * k}$ & 4.36 & $6.92^{* * *}$ & 0.88 \\
\hline Correlations & $\begin{array}{l}\text { Intercept } \\
\text { with } \\
\text { slope }\end{array}$ & $\sigma_{01}^{2}$ & .20 & & .32 & & .08 & & .19 & & .20 & & .05 & \\
\hline
\end{tabular}

Note: Par. - Parameter; CTRRPP - Comprehensive Tests of Reading Related Phonological Processing, WRMT-R - Woodcock Reading Mastery Test-Revised; TOWRE - Test of Word Reading Effidency.

${ }^{*} p<.05 .{ }^{* * t} p<.001$.

processes that does not require a verbal response. Children are presented with a series of increasingly complex geometric shapes to copy into a specific location within a response booklet. The test has been designed for ages 2 to 18. The Test of Visual-Perceptual Skills, 3rd Edition, Visual Sequential Memory subtest (TVPS-VSM; Gardner, 1988) is a mea- sure of nonverbal sequential memory. Children are presented a sequence of several shapes and have 1 minute until the shapes are removed and a target stimulus is presented with the original shape and three distracters. Recognition of the pattern that matches the original sequence of shapes is the target response.

WISC-III indices. The WISC-III (Wechsler, 1991) was part of the neurocognitive battery administered once to each child. The present analysis incorporates the four index scores that have emerged from factor analyses of the WISC- III subtests (Sattler, 1992). These four indices are as follows: Verbal Comprehension (VC), Perceptual Organization (PO), Freedom from Distractibility (FDI), and Processing Speed (PS).

\section{Analyses}

The overall analytic plan consisted of three steps. First, response to intervention was estimated via growth curve models applied to the six reading outcomes. Second, three categories of intervention response were formed for each outcome using the individually estimated growth rates generated by the growth models. Third, a series of discriminant function analyses (DFAs) was performed on these categories, using a fixed set of cognitive and neuropsychological measures to predict group membership and evaluate the relative contribution of individual predictors to classifying poor, average, and good responders for each outcome.

\section{Results}

\section{Estimating Relative Size of Reading Outcomes}

Individual growth curve models were formulated to define each participant's response to intervention. Across the 70 hours of intervention, three repeated measurements were taken on each outcome measure, providing sufficient resolution for a growth model with a random linear slope and random intercept. Visual inspection of individual growth curves did not provide evidence of curvilinear growth rates. 
Several quantifications of response to intervention were explored, including intercept only, intercept and slope together, and slope alone. In the analysis to follow each led to similar model results; thus, the slope-only model representing the number of items gained per 70 hours of intervention was used to quantify response to intervention. In the case of the Test of Transfer and the CTRRPP Blending, raw scores were used, and in the case of the WRMT-R subtests, Rasch-scaled $W$ scores were used as the scale of measurement. Mean growth rate per outcome, tests of random slopes and intercepts, and residual within-participant variation are reported in Table 2.

Three categories representing degree of response to intervention on each outcome were formed from these data. Because the current study was designed to investigate factors that contribute to suboptimal and excellent types of responses to intervention, the top $(n=56)$ and bottom $(n=56)$ quintiles were chosen to define these categories and maximize separation between them. The middle three quintiles were combined to form a category of average responders $(n=166)$. Table 3 details the response categories across the six outcomes. In general, the poor responders gained some reading skills across the six outcomes; in contrast, the good responders made consistently 3 to 4 times the gains of the poor responders. There was substantial overlap across out- comes on how participants were classified. Across the six outcomes, significant associations, $\chi 2$ (4) ranging from 6.74 to $120.97 ; \mathrm{M}=$ 40.03, $\mathrm{SD}=34.83$, were observed when any two classifications were paired (evaluated at $\alpha=.003$ to correct for multiple comparisons), with the exception of the pairing of the Test of Transfer, $\chi 2(4)=$ $6.74, \mathrm{p}=.15$, with CTRRPP Blending. Across all 15 combinations of classifications, the Cramer's V average effect size was 0.25 (range $=0.11$ to $0.47, \mathrm{SD}=0.11$ ), indicating moderate overlap in the response categories across the six outcomes.

Table 3. Gains Over Full Intervention for Three Response Categories

\begin{tabular}{|c|c|c|c|c|c|c|c|c|c|c|c|c|}
\hline & \multicolumn{2}{|c|}{$\begin{array}{c}\text { CTRRPP } \\
\text { Blending } \\
\text { (Raw Scores) } \\
\end{array}$} & \multicolumn{2}{|c|}{$\begin{array}{c}\text { WRMT-R } \\
\text { Word Att. (W } \\
\text { Scores) }\end{array}$} & \multicolumn{2}{|c|}{$\begin{array}{c}\text { Test of } \\
\text { Transfer (Raw } \\
\text { Scores) }\end{array}$} & \multicolumn{2}{|c|}{$\begin{array}{l}\text { WRMT-R } \\
\text { Word Id. (W } \\
\text { Scores) }\end{array}$} & \multicolumn{2}{|c|}{$\begin{array}{l}\text { WRMT-R P. } \\
\text { Comp (W } \\
\text { Scores) }\end{array}$} & \multicolumn{2}{|c|}{$\begin{array}{l}\text { TOWRE S. } \\
\text { Word (Raw } \\
\text { Scores) }\end{array}$} \\
\hline & M & $S D$ & M & $S D$ & M & $S D$ & M & $S D$ & $M$ & $S D$ & $M$ & $S D$ \\
\hline Poor & 1.64 & 0.78 & 2.04 & 0.39 & 14.76 & 1.64 & 16.45 & 2.36 & 10.36 & 2.78 & 4.24 & 1.05 \\
\hline Average & 4.30 & 0.89 & 8.82 & 3.73 & 20.23 & 1.52 & 28.38 & 5.10 & 18.20 & 2.80 & 9.63 & 2.35 \\
\hline Good & 7.48 & 1.02 & 19.24 & 2.84 & 24.97 & 1.78 & 47.90 & 7.82 & 28.62 & 3.47 & 17.48 & 2.93 \\
\hline
\end{tabular}

Note: Par. = Parameter; CTRRPP = Comprehensive Tests of Reading Related Phonological Processing; WRMT-R = Woodcock Reading Mastery Test - Revised; TOWRE $=$ Test of Word Reading Efficiency. Poor and good responders $n=56$ per group; average responders $n=166$.

\section{DFA Base Model}

Two hierarchically nested discriminant function models were constructed. To evaluate the utility of intervention condition and phonological and language measures to explain response categories, the first discriminant function model incorporated intervention condition, the Elision subtest from the CTRRPP, and the Numbers subtest from the Rapid Automatized Naming task to predict membership in the three categories of response. Intervention condition was entered into the model using a priori single degree of freedom contrasts as follows: (a) Contrast 1 compared the control condition of MATH+CSS to all three reading interventions together, (b) Contrast 2 compared single component reading intervention (PHAB/DI+CSS) to multiple component interventions, and (c) Contrast 3 directly contrasted PHAB/DI+WIST to PHAB/DI+RAVE-O. Elision and Rapid Automatized Naming Numbers were entered into the model along with these contrasts as $z$ score conversions based on the prepublication norms available at the time the tests were administered.

There were no missing data across all outcome measures, and minimal missing data were present across the predictors (6.5\%). Exploratory analyses comparing participants with missing and nonmissing data points indicated that the pattern was likely ignorable and randomly distributed across predictors. Expectation maximization imputation was used to create a full data set for the DFAs. Evaluation of assumptions for both this model and the additive model described below revealed 
moderate violation of the homogeneity of variances across the three response groups for three out of six outcomes. As a result, a quadratic discriminant function was performed for those outcomes. All other DFA assumptions (e.g., linearity, normality, and multicollinearity) were found to hold with the current data.

For each of the six outcomes, two discriminant functions were extracted (see Table 4 for $\chi^{2}$ and percentage variability accounted for values); however, in only one case was the second function significant after the first function was removed (WRMT-R Passage Comprehension), $F(4,272)=2.89, p$ $=.02$. For all outcomes, examination of the group centroids indicated that the first function equally separated the three response categories from each other. In both the base and the additive model described below, semipartial univariate results per predictor were also evaluated, correcting for multiple comparisons via Sidak's formula. Thus, in the base model, univariate results were evaluated at an alpha of .01. For all outcomes, Intervention Contrast 1 significantly separated the three response groups indicating that treatment versus control status significantly discriminated among groups. Intervention Contrast 2 also significantly separated the three response groups on the Test of Transfer and Word Attack, indicating that multiple component intervention significantly discriminated among groups for those outcomes. Intervention Contrast 3 did not significantly separate the three response groups on any of the outcomes. Elision significantly separated groups at the univariate level on the all outcomes but Blending Words and TOWRE Sight Words. Table 4 details the univariate results across the six discriminant function base models.

Table 4. Intervention and Phonology Discriminant Function Models, Reporting on Only the First Discriminant Function

\begin{tabular}{|c|c|c|c|c|c|c|}
\hline & \multicolumn{6}{|c|}{ Reading Outcome } \\
\hline & $\begin{array}{l}\text { CTRRPP } \\
\text { Blending }\end{array}$ & $\begin{array}{l}\text { WRMT-R } \\
\text { Word Att. }\end{array}$ & $\begin{array}{l}\text { Test of } \\
\text { Transfer }\end{array}$ & $\begin{array}{l}\text { WRMT-R } \\
\text { Word Id. }\end{array}$ & $\begin{array}{c}\text { WRMT-R P. } \\
\text { Comp. }\end{array}$ & $\begin{array}{l}\text { TOWRE S. } \\
\text { Word }\end{array}$ \\
\hline Model $F(10,542)$ & $3.62 *$ & $7.79 *$ & $13.94 *$ & $2.16^{*}$ & $4.70^{*}$ & $10.00 *$ \\
\hline Canonical corr. & .32 & .47 & .60 & .26 & .34 & .51 \\
\hline Eigenvalue & .11 & .28 & .57 & .07 & .13 & .36 \\
\hline \multicolumn{7}{|c|}{ Univariate semipartial tests, $F(2,275)$} \\
\hline Contrast I & $14.30^{*}$ & $17.48 *$ & $11.54 *$ & $8.15^{*}$ & $8.38 *$ & $11.89 *$ \\
\hline Contrast 2 & 1.79 & $7.28^{*}$ & $6.02 *$ & 1.45 & $3.59 *$ & 2.53 \\
\hline Contrast 3 & 0.68 & 2.37 & 0.48 & 0.38 & 1.42 & 1.41 \\
\hline RAN Let. & 1.44 & 3.67 & $20.10^{*}$ & 0.15 & $6.8 I^{*}$ & $21.51 *$ \\
\hline Elision & 0.06 & $8.00^{*}$ & $36.90 *$ & 0.86 & $4.78 *$ & $17.80 *$ \\
\hline \multicolumn{7}{|c|}{ Standardized discriminant coefficients (only $>.25$ reported) } \\
\hline Contrast I & .97 & .83 & .61 & .92 & .73 & .60 \\
\hline Contrast 2 & & .45 & .25 & .29 & & \\
\hline \multicolumn{7}{|l|}{ Contrast 3} \\
\hline RAN Let. & & .29 & .47 & & .50 & .66 \\
\hline Elision & & .38 & .68 & .28 & .42 & .52 \\
\hline
\end{tabular}

Note: CTRRPP - Comprehensive Tests of Reading Related Phonological Processing; WRMT-R - Woodcodk Reading Mastery Tests-Revised; TOWRE - Test of Word Reading Effidency, RAN - Rapid Automatized Naming. The three orthogonal contrasts were as follows: Contrast I - intervention vs. control; Contrast 2 - multiple component vs. single component Intervention; Contrast 3 - Phonological and Strategy Training vs. Retrieval, Automatidty, Vocabulary Elaboration, Orthography.

$* p<.01$.

The standardized discriminant coefficients $(\beta \mathrm{dc})$ were examined to determine the relative importance of each predictor. The coefficients represent the influence of each variable on the discriminant function, controlling for all other variables, and were evaluated against a criterion of .30. For all outcomes, Intervention Contrast 1 was consistently an important predictor based on this criterion, particularly for the Blending Words, Word Identification, and Passage comprehension outcomes ( $\beta_{\mathrm{dc}}$ ranging from .60 to .97). For the Test of Transfer, Passage Comprehension, and TOWRE Sight Words outcomes, rapid naming was an important and unique predictor $\left(\beta_{\mathrm{dc}}\right.$ ranging from .47 to .66). For these same outcomes and for Word Attack, Elision was an important and unique predictor $\left(\beta_{\mathrm{dc}}\right.$ 
ranging from .38 to .68). Post hoc comparisons of mean levels of Elision and Letter Naming per outcome indicated an overall pattern of poor responders having lower scores compared to average and good responders, who were not different from each other. In contrast, good responders on the Test of Transfer and the TOWRE Sight Words had better Elision scores and faster Letter Naming speeds than average responders.

\section{DFA Cognitive and Neuropsychological}

\section{Additive Model}

Nested models relative to the base model described above were formed by including eight neurocognitive process predictors along with the previously evaluated intervention contrasts, Elision, and Blending Words. The goals of the nested models were as follows: (a) to evaluate which cognitive and neuropsychological predictors contributed to the discriminant function, controlling for intervention, PA, and rapid naming; and (b) to establish if predictive power could be enhanced by the inclusion of this class of predictors and specifically how this improvement functions.

In the additive model, univariate results were evaluated at an alpha of .oo4, using Sidak' s formula to correct for multiple tests. As can be seen in Table 5 , a range of cognitive and neuropsychological predictors significantly explained membership in the response categories. The standardized discriminant coefficients $\left(\beta_{\mathrm{dc}}\right)$ were examined to investigate the relative importance of each predictor, controlling for all other additive predictors including those in the base model. Even with all additive predictors in the model, the coefficients for Contrast 1 remained significant, indicating that treatment status continued to explain membership in the response categories. Rapid naming and elision remained unique and important predictors across WRMT-R Word Attack, Passage Comprehension, Test of Transfer, and TOWRE Sight Words.

Among the neurocognitive process predictors, the WISCIIIVC factor explained unique variance in response categories across the six outcomes ( $\beta_{\mathrm{dc}}$ ranging from .25 to .75). A similar pattern of post hoc differences among the response categories was observed, with poor responders having lower VC scores than average and good responders, who were not different from each other. In contrast, good responders on the Test of Transfer and the TOWRE Sight Words had better VC scores than average responders. The VMI remained a significant predictor of response on the Blending and Word Attack outcomes, in both cases with high VMI scores predicting better response across all response categories. WISC-III FDI and PS predicted responses on Blending, but only separating good responders from average and poor, who did not differ from each other on these cognitive variables. For the remaining effects of particular cognitive or neuropsychological predictors explaining response, the following pattern was observed: Poor responders had low scores on the predictor, separating them from good and aver- age responders, who did not differ from each other. This pattern held for Nonword Repetition predicting Test of Transfer response, PO predicting Word Attack response, VSM predicting Word Identification response, and WISC- III PS predicting Passage Comprehension response. 
Table 5. Final Additive Discriminant Model Overall and Univarlate Predictor Results

\begin{tabular}{|c|c|c|c|c|c|c|}
\hline & \multicolumn{6}{|c|}{ Reading Outcome } \\
\hline & $\begin{array}{l}\text { CTRRPP } \\
\text { Blending }\end{array}$ & $\begin{array}{l}\text { WRMT-R } \\
\text { Word Att. }\end{array}$ & $\begin{array}{l}\text { Test of } \\
\text { Transfer }\end{array}$ & $\begin{array}{l}\text { WRMT-R } \\
\text { Word Id. }\end{array}$ & $\begin{array}{l}\text { WRMT-R P. } \\
\text { Comp. }\end{array}$ & $\begin{array}{l}\text { TOWRE S. } \\
\text { Word }\end{array}$ \\
\hline Model $F(26,526)$ & $2.45^{*}$ & $4.67^{*}$ & $6.57^{*}$ & $1.7 I^{*}$ & $3.06 *$ & 4.93 \\
\hline Canonical corr. & .40 & 54 & .65 & .33 & .43 & .55 \\
\hline Elgenvalue & .19 & .41 & .72 & .13 & .23 & .44 \\
\hline \multicolumn{7}{|c|}{ Unlvarlate semipartial tests, $F(2,275)$} \\
\hline Beery VMI & 4.46 & $7.27^{*}$ & $6.84 *$ & 1.77 & 5.38 & 2.39 \\
\hline Memory for Words & 1.26 & 1.96 & 1.85 & 2.70 & 5.09 & 4.75 \\
\hline Nonword Rep. & 1.82 & $7.65^{*}$ & 3.34 & 1.88 & 3.40 & 3.52 \\
\hline TVPSVSM & 1.24 & 1.07 & $7.38^{*}$ & 2.67 & 3.88 & 4.27 \\
\hline WISC-III FDI & 2.58 & 2.42 & $10.33^{*}$ & 3.29 & 6.01 & $8.85^{*}$ \\
\hline WISC-III PO & 1.61 & $5.82 *$ & $14.29^{*}$ & 3.10 & 5.36 & 5.38 \\
\hline WISC-III PS & 3.03 & 1.77 & 3.91 & 0.34 & $10.1^{*}$ & $5.85^{*}$ \\
\hline WISC-IIIVC & 0.34 & $5.89^{*}$ & $14.02^{*}$ & 4.74 & 4.90 & $7.68^{*}$ \\
\hline \multicolumn{7}{|c|}{ Standardized discriminant coefficlents ( $\beta_{d k}>.25$ reported) } \\
\hline Contrast I & .75 & .80 & .61 & .77 & .60 & .59 \\
\hline Contrast 2 & & .33 & & & & \\
\hline \multicolumn{7}{|l|}{ Contrast 3} \\
\hline RAN Let. & & .34 & .54 & & .32 & .66 \\
\hline Elision & & & .57 & & & .35 \\
\hline Beery VMI & .46 & .36 & & & & \\
\hline \multicolumn{7}{|l|}{ Memory for Words } \\
\hline Nonword rep. & & .40 & & & & \\
\hline TVPSVSM & & & & .30 & & \\
\hline WISC-III FDI & .27 & & & & & \\
\hline WISC-III PO & & & .33 & & & \\
\hline WISC-III PS & .27 & & & & .34 & \\
\hline WISC-IIIVC & .75 & .25 & .61 & .42 & .60 & .59 \\
\hline
\end{tabular}

Note: CTRRPP — Comprehensive Tests of Reading Related Phonological Processing; WRMT-R - Woodcack Reading Mastery Tests-Revised; TOWRE - Test of Word Reading Efficiency; VMI - visual-motor integration; TVPS-VSM - Test of Visual-Perceptual Skills Visual Sequential Memory subtest; WISC-III Wechsler Intelligence Scale for Children-Third Edition; FDI - Freedom from Distractibility Scaled Score; PO - Perceptual Organization Scaled Score;

PS - Processing Speed Scaled Score; VC - Verbal Comprehension Scaled Score. The three orthogonal contrasts were as follows: Contrast

I - intervention vs. control; Contrast 2 - multiple component vs. single component intervention; Contrast 3 - Phonological and Strategy Training vs.

Retrieval, Automaticity, Vocabulary Elaboration, Orthography.

${ }^{*} p<.004$.

\section{Follow-Up Analysis of Change in Classification Errors From Base to Additive Model}

The goal of the present analysis was not classification per se. However, an examination of the classification error rates was conducted to further characterize the utility of the cognitive and neuropsychological predictors in explaining the relative size of the reading outcome. The first error rate analysis consisted of comparisons between models in the overall improvement in reclassification. The proportion of misclassifications unique to the base model minus misclassifications unique to the additive model squared, divided by the sum of these two is distributed as a $\chi 2$ with one degree of freedom. When applied to each outcome, significantly greater correct reclassification was observed for every out- come model, except WRMT-R Word Identification. Table 6 details the $\chi^{2}$ tests for each outcome. These analyses indicate that the additive model improved classification over the base model. 
Table 6. Comparison of Intervention-Phonology and Cognitive-Neuropsychological Additive Model

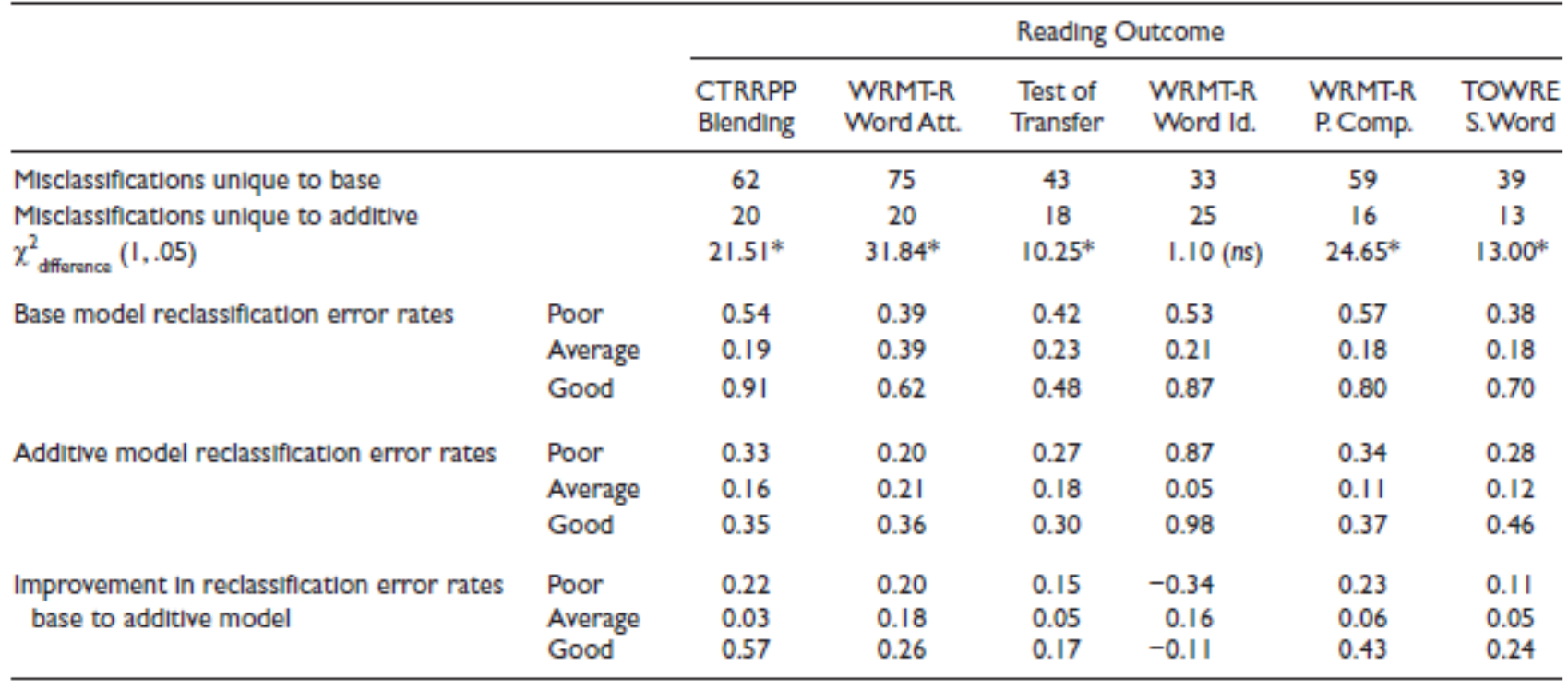

Note: CTRRPP = Comprehensive Tests of Reading Related Phonological Processing;WRMT-R = Woodcock Reading Mastery Tests-Revised;TOWRE = Test of Word Reading Efficiency. Poor and good responders $n=56$ per group; average responders $n=166$.

$* 0.01$.

The second error rate analysis consisted of examining changes in the errors of classification across the three response categories from the base to the additive model. The base model was more effective in classifying the poor res- ponders, with average error rates across the six outcomes $25 \%$ below the error rate of classifying good responders. With the addition of cognitive and

neuropsychological predictors, classification improved markedly with lower error rates across the three response categories. On Blending Words, WRMT-R Passage Comprehension, and TOWRE Sight Word reading, the improvement in classifying good responders was twice the improvement of classifying poor responders. On WRMT-R Word Attack and Test of Transfer, roughly equal improvement was seen in classifying poor and good responders. Table 6 details the base and additive model error rates, along with tests of improvement to classification error rates.

\section{Discussion}

The present study was conducted to establish whether reliable predictors of reading processes are also predictive of relative size of reading outcomes in the context of intensive remedial reading instruction. Among the potential neuro- cognitive processes that have been shown to relate to the process of reading, the present study considered whether short-term memory, visual memory, and specific components of IQ moderated degree of response to reading intervention among young struggling readers. A particular focus of this study was to evaluate the profile of neurocognitive processes that explained poor, average, or good relative sizes of reading outcomes.

Results from the present study suggest that phonological memory, cognitive, and visual processing predictors do have predictive value in explaining response to intervention among children with RD. These effects were demonstrated above and independent of the contributions of multiplecomponent intervention, PA, and rapid naming skill. As supported by extensive empirical and theoretical work on RD, PA and rapid naming significantly distinguished the three degrees of response. Slow naming speed and poor PA in particular separated poor responders from both average and good responders. This pattern held across all outcomes except the two requiring rapid responses (i.e., Test of Transfer and TOWRE Sight Words), on which faster naming and better PA separated the three groups in a continuous function.

The specific contribution of the additive predictors was to improve classification accuracy of both poor and good responders, with a notable advantage in classifying who was a good responder. 
Excluding WRMT-R Word Identification, for which the additive predictors did not improve classification, incorporating the cognitive and neuropsychological variables improved classification of poor responders on average by $\mathbf{1 8 . 2} \%$. Across a broad range of reading skills-phonological blending, comprehension, and fluency-the cognitive and neuropsychological predictors improved classification of good responders by twice the amount for poor responders, an average of $41.3 \%$. On the three measures of single word reading or nonword decoding, the improvement to classifying good responders was equivalent to the improvement in classifying poor responders.

These results are consistent with Vellutino's (2001) suggestion that cognitive processes may be correlated more strongly with reading comprehension while less strongly correlated with more basic reading skills, such as nonword reading and word identification. On the surface, the present results may be viewed as inconsistent with those of Johnston and Morrison (2007), who found that high-IQ poor readers were more phonologically impaired than low-IQ poor readers and had relatively more difficulty decoding new words and non- words. However, in the context of phonologically intense instruction, higher IQ versus low IQ was associated with greater response-that is, benefit. This finding highlights the need to consider carefully past correlational results linking cognitive and neuropsychological factors with reading acquisition. Static predictors of reading ability or the reading process may not demonstrate relationships, whereas the same predictors may explain reading outcomes when related to response or rate of growth. Results from the present study are consistent with this perspective, given that the degree of response on the two phonologically based outcomesBlending Words and WRMT-R Word Attack-was uniquely predicted by the greatest number of neurocognitive process predictors (see standardized discriminant coefficients reported in Table 5). The addition of neuropsychological predictors increased the classification accuracy for poor and good responders on phonological blending skill by 22 and $57 \%$ respectively, consistent with Torgesen and Davis (1996).

At the univariate level, the pattern of significant predictors was linked to the underlying reading process that each outcome represents. These relationships were supported by interpretation of the standardized discriminant coefficients, which fully partial out the effect of intervention, PA, and rapid naming skills. For example, growth in phonological blending skills was explained by VMI and the FDI of the WISC-III. Vellutino et al. (2000) have shown that there may be a stronger relationship for VIQ than PIQ with reading outcomes, with the strongest relationship for younger children in their sample. This is consistent with the present results, with the WISC-III VC index a statistically significant and notable predictor of degree of response across all outcomes. As indicated by the standardized discriminant coefficients in Table 5, VMI, Nonword Repetition, and the WISC-III indices of FDI, PS, and VC each played a role in predicting degree of response for these outcomes. The present sample was a younger sample, with participants ranging from Grade 1 to Grade 3. As such, the results highlighting the importance of naming speed are consistent with the current literature, which shows a greater influence of naming speed on early reading development, with less influence after Grade 3 (Wolf, Bowers, et al., 2000). The present sample also had significantly impaired reading skills, and thus the present results are consistent with a recent large-scale and longitudinal study that found RAN to be a more important predictor for the poorest readers (Lervåg, Bråten, \& Hulme, 2009).

The results of the present study are consistent with Vellutino et al.'s (2000) reanalysis of Vellutino et al. (1996; see also Scanlon \& Vellutino, 1997), who found that IQ did not predict growth in reading comprehension or word identification for children in the good or very good growth rate groups. The two exceptions to this in the present study involve the measures of transfer of learning (i.e., Test of Transfer) and fluency (i.e., TOWRE Sight Word). Both are measures of single word identification with a significant speeded component. In the former, children are presented with single words that persist a limited amount of time on a computer display; in the latter, children are instructed to read a list of words as quickly as possible. Both of these tasks are demanding on a skill integration level and tax multiple and independent cognitive and perceptual systems. In the present study, additional cognitive capability did distinguish between the best responders and the average or lower responders. This finding is also consistent with the review by Fuchs and Young (2006), which suggested that cognitive 
and neuropsychological predictors were more predictive of intervention response when the instructional focus was on more complex reading tasks.

\section{Limitations}

Given the current state of research into the factors that predict responsiveness to intervention, the present analysis was conducted in an exploratory manner, preserving individual outcomes and the individual predictors. At the outcome level, this decision is supported by the tests of association across classifications derived from the six reading measures. Although the association from measure to measure on who was a good, average, or poor responder was statistically significant and of moderate effect size, the association was not perfect. Though some of the disagreement is attributable to the reliability of these outcome measures, all out- come measures demonstrated excellent psychometric properties as previously reviewed. This finding suggests that each reading measure had unique ability to separate degree of response and suggests that studies on intervention responsiveness should take care to incorporate multiple dimensions of reading process.

At the predictor level, it is likely that these predictors are components of a smaller number of dimensions, which may or may not relate to intervention response. An additional argument for retaining the individuality of the predictors is that those included in the present study are a select group that notably excluded orthographic processing (e.g., Mano \& Osmon, 2008), executive function (Reiter, Tucha, \& Lange, 2005), and working memory (e.g., Swanson \& Jerman, 2007), among others. A dimensionality analysis in the present con- text would inevitably result in a measure-dependent oversimplification of the variable set. Regardless, an exploratory post hoc exploratory factor analysis of the present measures indicated three factors: a phonological processing factor that consisted of Elision and Letter Naming, a memory factor that consisted of Nonword Repetition and Memory for Words, and a general cognitive factor that included all of the other study predictors. A comprehensive structural model could be envisioned that would combine such a dimensionality analysis with a structural analysis of differing relationships between neurocognitive predictors and the type of reading outcome involved. Such a model would explicitly model the suggestions within the present analysis that neurocognitive predictors share a stronger relationship with the more multidetermined reading processes (e.g., comprehension, fluency-based outcomes, etc.).

To preserve the richness of exploration across multiple predictors and outcomes, the present analysis did not con- sider interactions of cognitive and neuropsychological predictors with the particular interventions involved. Half of the sample participated in multiple component interventions that emphasized direct training of phonological skills and orthography combined with either metacognitive strategy instruction (PHAST; Lovett et al., 2000) or fluency and vocabulary building instruction (RAVE-O; Wolf, Miller, et al., 2000). With 70 participants in each of the control and $\mathrm{PHAB} / \mathrm{DI}$ conditions, incorporating interactions between cognitive predictors and intervention type would have necessitated dropping several predictors.

It is important to note that the present study considered the association of cognitive and neuropsychological measures with the degree of response to intervention from a variable-centric perspective. This perspective emphasizes overall relationships among constructs and speaks very minimally to the dynamics for particular individuals. Particular component skills that have been demonstrated to moderate response to intervention may be targets for pre- or simultaneous intervention. Gathercole and Alloway (2006) recently described how short-term and working memory are amenable to intervention, with an emphasis on both strategies to compensate for deficits in these areas and training to expand capacity. Thus, at the level of practice, the present study supports the use and inclusion of a broader range of cognitive and neuropsychological factors as targets for generating individualized hypotheses about intransigent reading difficulties (for a description of such an approach, see Fiorello et al., 2006).

\section{Implications for Intervention Architectures}

Overall, the present analysis suggests that predictors of rea- ding outcomes for young children with RD 
may need to be conceptualized more broadly than phonological analysis and rapid naming skill alone. Such a broader conceptualization has been illustrated by the recent evaluation of the convergent skills model by Vellutino, Tunmer, Jaccard, and Chen (2007). This type of integrated and theory-driven model that includes language-based processes along with component memory and visual skills may help expand a full understanding of who does and does not respond to generally efficacious interventions. In the context of for- mal response to intervention (RTI) programs and implementations, research-based interventions that focus on decoding and fluency processes have been shown to be effective for early readers and for struggling readers. On the weight of the present results and of past research, Tier 1 and Tier 2 RTI protocols are well justified in implementing these types of interventions.

As recent neuroimaging work has shown, phonological and word-rate-focused interventions can lead to a shift in processing for children with $\mathrm{RD}$ from the right to the left hemisphere (see Richards \& Berninger, 2008; Richards et al., 2007, Simos et al., 2007a, 2007b). In this research, children with $\mathrm{RD}$ displayed an overactive profile in areas typically associated with visual processing prior to intensive reading intervention. After intervention, both functional magnetic resonance imaging and magnetic source imaging scans showed a "normalization" pattern, with decreased right hemispheric (occipitoteporal) and increased left hemispheric (e.g., temporoparietal) processing areas used by fluent, nonimpaired readers for phonologically based tasks. Consistent with the present findings that showed an important role for visual, verbal, and memory neurocognitive processes, this neuroimaging work suggests that reading outcomes are multidetermined and dynamic. This may be especially true when the focus shifts to poor or even nonresponders, as shown in the work by Simos and colleagues (2007a, 2007b). In these studies, children who did not make clinically significant gains to intensive phonological intervention did not show the same normalization, continuing to rely on alternate brain regions to accomplish decoding and phonological tasks. In these cases, both recent imaging studies and the present results suggest that a comprehensive evaluation of neurocognitive processes may be needed to support the development of more individualized interventions (Hale, Kaufman, Naglieri, \& Kavale, 2006).

\section{Declaration of Conflicting Interests}

The authors declared no potential conflicts of interests with respect to the authorship and/or publication of this article.

\section{Financial Disclosure/Funding}

The authors disclosed receipt of the following financial support for the research and/or authorship of this article:

The research reported here was supported by a National Institutes of Child Health and Human Development Grant (HD30970) to Georgia State University, Tufts University, and The Hospital for Sick Children/University of Toronto. 


\section{References}

Al Otaiba, S., \& Fuchs, D. (2002). Characteristics of children who are unresponsive to early literacy intervention: A review of the literature. Remedial and Special Education, 23, 300-316.

Baddeley, A. D. (1986). Working memory. Oxford, UK: Oxford University Press.

Beery, K. E., \& Buktenica, N. A. (1989). Developmental Test of Visual-Motor Integration. Odessa, FL: Psychological Assessment Resources.

Berninger, V. W., Raskind, W., Richards, T., Abbott, R., \& Stock, P. (2008). A multidisciplinary approach to understanding developmental dyslexia within working-memory architecture: Genotypes, phenotypes, brain, and instruction. Developmental Neuropsychology, 33, 707-744.

Block, C. C., Parris, S. R., Reed, K. L., Whiteley, C. S., \& Cleveland, M. D. (2009). Instructional approaches that significantly increase reading comprehension. Journal of Educational Psychology, 101, 262-281.

Braden, J. P., \& Shaw, S. R. (2009). Intervention validity of cognitive assessment: Knowns, unknowables, and unknowns. Assessment for Effective Intervention, 34, 106-115.

Cirino, P. T., Rashid, F. L., Sevcik, R. A., Lovett, M. W., Frijters, J. C., Wolf, M., \& Morris, R. (2002). Properties of measures of beginning decoding and related abilities in poor readers. Journal of Learning Disabilities, 35, 526-539.

Denckla, M. B., \& Rudel, R. G. (1974). Rapid "automatized" naming of pictured objects, colors, letters, and numbers by normal children. Cortex, 10, 186-202.

Denckla, M. B., \& Rudel, R. G. (1976). Naming of objects by dyslexic and other learning-disabled children. Brain \& Language, 3, 1-15.

Engelmann, S., \& Bruner, E. C. (1988). Reading Mastery I/II fast cycle: Teacher's guide. Chicago, IL: Science Research Associates.

Evans, J. J., Floyd, R. G., McGrew, K. S., \& Leforgee, M. H. (2001). The relations between measures of Cattell-Horn-Carroll (CHC) cognitive abilities and reading achievement during childhood and adolescence. School Psychology Review, 31(2), 246-262.

Fiorello, C. A., Hale, J. B., \& Snyder, L. E. (2006). Cognitive hypothesis testing and response to intervention for children with reading problems. Psychology in the Schools, 43, 835-853.

Fletcher, J. M., Lyon, G. R., Barnes, M., Stuebing, K. K., Francis, D. J., Olson, R. K., . . Shaywitz, B. A. (2002). Classification of learning disabilities: An evidenced-based evaluation. In R. Bradley, L. Danielson, \& D. Hallahan (Eds.), Identification of learning disabilities: Research to practice (pp. 185-239). Mahwah, NJ: Erlbaum.

Fletcher, J. M., Shaywitz, S. E., Shankweiler, D. P., Katz, L., Liberman, I. Y., Stuebing, K. K., . . Shaywitz, B. A. (1994). Cognitive profiles of reading disability: Comparisons of discrepancy and low achievement definitions. Journal of Educational Psychology, 85, 1-18.
Floyd, R. G., Keith, T. Z., Taub, G. E., \& McGrew, K. S. (2007). Cattell -Horn -Carroll cognitive abilities and their effects on reading decoding skills: $\mathrm{g}$ has indirect effects, more specific abilities have direct effects.School Psychology Quarterly, 22, (2) 200-233.

Fuchs, D., \& Young, C. L. (2006). On the irrelevance of intelligence in predicting responsiveness to reading instruction. Exceptional Children, 73, 8-30.

Gardner, M. E. (1988). Test of Visual-Perceptual Skills. San Francisco, CA: Health Publishing.

Gathercole, S. E. (2006). Nonword repetition and word learning: The nature of the relationship. Applied Psycholinguistics, 27, 513-543.

Gathercole, S. E., \& Alloway, T. P. (2006). Practitioner Review: Short-term and working memory impairments in neurodevelopmental disorders: diagnosis and remedial support. Journal of Child Psychology and Psychiatry, 47, (1), 4-15.

Gathercole, S. E., Alloway, T. P., Willis, C., \& Adams, A.-M. (2005). Working memory in children with reading disabilities. Journal of Experimental Child Psychology, 93, 265-281.

Gathercole, S. E., \& Baddeley, A. D. (1990). The role of phonological memory in vocabulary acquisition: A study of young children learning new names. British Journal of Psychology, 81, 439-454.

Glutting, J. J., Watkins, M. W., Konold, T. R., \& McDermott, P. A. (2006). Distinctions without a difference: The utility of observed versus latent factors from the WISC-IV in estimating reading and math achievement on the WIAT-II. Journal of Special Education, 40, 103-114.

Grogan, S. C. (1995). Which cognitive abilities at age four are the best predictors of reading ability at age seven? Journal of Research in Reading, 18, 24-31.

Gustafson, S., \& Samuelsson, S. (1999). Intelligence and dyslexia: Implications for diagnosis and intervention. Scandinavian Journal of Psychology, 40, 127-134.

Hale, J. B., Fiorello, C. A., Kavanagh, J. A., Holdnack, J. A., \& Aloe, A. M. (2007). Is the demise of IQ interpretation justified? A response to special issue authors. Applied Neuropsychology, 14, 37-51.

Hale, J. B., Kaufman, A., Naglieri, J. A., \& Kavale, K. A. (2006). Implementation of idea: Integrating response to intervention and cognitive assessment methods. Psychology in the Schools, 43, 753-770.

Hicks, C. (1980). The ITPA visual sequential memory task: An alternative interpretation and the implications for good and poor readers. British Journal of Educational Psychology, 50, $16-25$.

Hoskyn, M., \& Swanson, H. L. (2000). Cognitive processing of low achievers and children with reading disabilities: A selec- tive meta-analytic review of the published literature. School Psychology Review, 29, 102-119.

Huba, M. E., Vellutino, F. R., \& Scanlon, D. M. (1990). Auditory and visual retention in poor and normal readers when verbal 
encoding is disrupted. Learning and Individual Differences, 2, 95-112.

Johnston, R. S., \& Morrison, M. (2007). Toward a resolution of inconsistencies in the phonological deficit theory of reading disorders: Phonological reading difficulties are more severe in high-IQ poor readers. Journal of Learning Disabilities, 40, 66-79.

Kaufman, A. S., \& Kaufman, A. L. (1990). Kaufman Brief Intelligence Test. Circle Pines, MN: American Guidance Service.

Kavale, K. A. (1982). Meta-analysis of the relationship between visual perceptual skills and reading achievement. Journal of Learning Disabilities, 15, 42-51.

Kirby, J. R., Parrila, R. K., \& Pfeiffer, S. L. (2003). Naming speed and phonological awareness as predictors of reading development. Journal of Educational Psychology, 95, 453-464.

Lervåg, A., Bråten, I., \& Hulme, C. (2009). The cognitive and linguistic foundations of early reading development: A Norwegian latent variable longitudinal study. Developmental Psychology, 45, 764-781.

Liberman, I. Y., \& Shankweiler, D. (1985). Phonology and the problems of learning to read and write. Reading and Special Education, 6(6), 8-17.

Lovett, M. W., Barron, R. W., \& Benson, N. J. (2003). Effective remediation of word identification and decoding difficulties in school-age children with reading disabilities. In H. L. Swanson, K. R. Harris, \& S. Graham (Eds.), Handbook of learning disabilities (pp. 273-292). New York, NY: Guilford.

Lovett, M. W., De Palma, M., Frijters, J. C., Steinbach, K., Temple, M., Benson, N., \& Lacerenza, L. (2008). Interventions for reading difficulties: A comparison of response to intervention by ELL and EFL struggling readers. Journal of Learning Disabilities, 41, 333-352.

Lovett, M. W., Lacerenza, L., \& Borden, S. L. (2000). Putting struggling readers on the PHAST track: A program to integrate phonological and strategy-based remedial reading instruction and maximize outcomes. Journal of Learning Disabilities, 33 , 458-476.

Lovett, M. W., Lacerenza, L., Borden, S. L., Frijters, J. C., Steinbach, K. A., \& De Palma, M. (2000). Components of effective remediation for developmental reading disabilities: Combining phonological and strategy-based instruction to improve outcomes. Journal of Educational Psychology, 92, 263-283.

Lovett, M. W., Lacerenza, L., Murphy, D., Steinbach, K. A., De Palma, M., \& Frijters, J. C. (2005). The importance of multiple-component interventions for children and adolescents who are struggling readers. In J. Gilger \& S. Richardson (Eds.), Research-based education and intervention: What we need to know (pp. 67-102). Baltimore, MD: International Dyslexia Association.

Manis, F. R., Seidenberg, M. S., \& Doi, L. M. (1999). See Dick RAN: Rapid naming and the longitudinal prediction of reading subskills in first and second graders. Scientific Studies of Reading, 3, 129-157.
Mano, Q. R., \& Osmon, D. C. (2008). Visuoperceptualorthographic reading abilities: A confirmatory factor analysis study. Journal of Clinical and Experimental Neuropsychology, 30, 421-434.

Metsala, J. L., Stavrinos, D., \& Walley, A. C. (2009). Children's spoken word recognition and contributions to phonological awareness and nonword repetition: A 1-year follow-up. Applied Psycholinguistics, 30, 101-121.

Morris, R. D., Lovett, M. W., Wolf, M., Sevcik, R. A., Steinbach, K. A., Frijters, J. C., \& Shapiro, M. (in press). Multiplecomponent remediation for developmental reading disabilities: IQ, SES, and race as factors on remedial outcome. Journal of Learning Disabilities. Advance online publication. doi: 10.1177/0022219409355472.

Nelson, J. R., Benner, G. J., \& Gonzalez, J. (2003). Learner characteristics that influence the treatment effectiveness of early literacy interventions: A meta-analytic review. Learning Disabilities Research \& Practice, 18, 255-267.

Oh, H.-J., Glutting, J. J., Watkins, M. W., Youngstrom, E. A., \& McDermott, P. A. (2004). Correct interpretation of latent versus observed abilities: Implications from structural equation modeling applied to the WISC-III and WIAT linking sample. Journal of Special Education, 38, 159-173.

O’Malley, K. J., Francis, D. J., Foorman, B. R., Fletcher, J. M., \& Swank, P. R. (2002). Growth in precursor and reading-related skills: Do low-achieving and IQ-discrepant readers develop differently? Learning Disabilities Research \& Practice, 17, 19-34.

Reiter, A., Tucha, O., \& Lange, K. W. (2005). Executive functions in children with dyslexia. Dyslexia: An International Journal of Research and Practice, 11, 116-131.

Richards, T. L., \& Berninger, V. (2008). Abnormal fMRI connectivity in children with dyslexia during a phoneme task: Before but not after treatment. Journal of Neurolinguistics, 21, 294-304.

Richards, T. L., Berninger, V., Winn, W., Stock, P., Wagner, R., Muse, A., \& Maravilla, K. (2007). Functional MRI activation in children with and without dyslexia during pseudoword aural repeat and visual decode: Before and after treatment. Neuropsychology, 21, 732-741.

Sattler, J. M. (1992). Assessment of children (3rd ed.). San Diego, CA: Jerome M. Sattler.

Scanlon, D. M., \& Vellutino, F. R. (1997). A comparison of the instructional backgrounds and cognitive profiles of poor, average, and good readers who were initially identified as at risk for reading failure. Scientific Studies of Reading, 1, 191-215.

Scarborough, H. S. (1998). Predicting the future achievement of second graders with reading disabilities: Contributions of phonemic awareness, verbal memory, rapid naming, and IQ. Annals of Dyslexia, 48, 115-136.

Schatschneider, C., Fletcher, J. M., Francis, D. J., Carlson, C. D., \& Foorman, B. R. (2004). Kindergarten prediction of reading skills: A longitudinal comparative analysis. Journal of Educational Psychology, 96, 265-282. 
Scheiman, M., \& Rouse, M. W. (2005). Optometric management of learning-related vision problems. New York, NY: C. V. Mosby.

Scruggs, T. E., \& Mastropieri, M. A. (2003). Issues in the identification of learning disabilities. In T. E. Scruggs \& M. A. Mastropieri (Eds.), Identification and assessment: Advances in learning and behavior disabilities (pp. 1-36). Oxford, UK: Elsevier.

Siegel, L. S. (1989). IQ is irrelevant to the definition of learning disabilities. Journal of Learning Disabilities, 22, 469-479.

Siegel, L. S. (1992). An evaluation of the discrepancy definition of dyslexia. Journal of Learning Disabilities, 25, 618-629.

Simos, P. G., Fletcher, J. M., Sarkari, S., Billingsley-Marshall, R., Denton, C. A., \& Papanicolaou, A. C. (2007a). Altering the brain circuits for reading through intervention: A magnetic source imaging study. Neuropsychology, 21, 485-496.

Simos, P. G., Fletcher, J. M., Sarkari, S., Billingsley-Marshall, R., Denton, C. A., \& Papanicolaou, A. C. (2007b). Intensive instruction affects brain magnetic activity associated with oral word reading in children with persistent reading disabilities. Journal of Learning Disabilities, 40, 37-48.

Stanovich, K. E., \& Siegel, L. S. (1994). Phenotypic performance profile of children with reading disabilities: A regression-based test of the phonological-core variable-difference model. Journal of Educational Psychology, 86, 24-53.

Stuebing, K. K., Fletcher, J. M., LeDoux, J. M., Lyon, G. R., Shaywitz, S. E., \& Shaywitz, B. A. (2002). Validity of IQdiscrepancy classifications of reading disabilities: A meta-analysis. American Educational Research Journal, 39, 469-518.

Swanson, H. L., \& Jerman, O. (2007). The influence of working memory on reading growth in subgroups of children with reading disabilities. Journal of Experimental Child Psychology, 96, 249-283.

Swanson, H. L., Trainin, G., Necoechea, D. M., \& Hammill, D. D. (2003). Rapid naming, phonological awareness, and reading: A meta-analysis of the correlational evidence. Review of Educational Research, 73, 407-444.

Swanson, H. L., Zheng, X., \& Jerman, O. (2009). Working memory, short-term memory, and reading disabilities: A selective meta-analysis of the literature. Journal of Learning Disabilities, 42, 260-287.

Tiu, R. D., Jr., Thompson, L. A., \& Lewis, B. A. (2003). The role of IQ in a component model of reading. Journal of Learning Disabilities, 36, 424-436.

Torgesen, J. K. (2005). Recent discoveries on remedial interventions for children with dyslexia. In M. J. Snowling \& C. Hulme (Eds.), The science of reading: A handbook (pp. 521-537). Oxford, UK: Blackwell.

Torgesen, J. K., Alexander, A. W., Wagner, R. K., Rashotte, C. A., Voeller, K. K. S., \& Conway, T. (2001). Intensive remedial instruction for children with severe reading disabilities: Immediate and long-term outcomes from two instructional approaches. Journal of Learning Disabilities, 34, 33-58.
Torgesen, J. K., \& Davis, C. (1996). Individual difference variables that predict response to training in phonological awareness. Journal of Experimental Child Psychology, 63, 1-21.

Torgesen, J. K., \& Wagner, R. K. (1996). The comprehensive test of reading related phonological processes. Tallahassee, FL: Author.

Vellutino, F. R. (2001). Further analysis of the relationship between reading achievement and intelligence: A response to Naglieri. Journal of Learning Disabilities, 34, 306-310.

Vellutino, F. R., Scanlon, D. M., \& Lyon, G. R. (2000). Differentiating between difficult-to-remediate and readily remediated poor readers. Journal of Learning Disabilities, 33, 223-238.

Vellutino, F. R., Scanlon, D. M., Sipay, E. R., Small, S. G., Pratt, A., Chen, R., et al. (1996). Cognitive profiles of dif- ficultto-remediate and readily remediated poor readers: Early intervention as a vehicle for distinguishing between cognitive and experiential deficits as basic causes of specific reading disability. Journal of Educational Psychology, $88,(4) 601-638$.

Vellutino, F. R., Tunmer, W. E., Jaccard, J. J., \& Chen, R. (2007). Components of reading ability: Multivariate evidence for a convergent skills model of reading development. Scientific Studies of Reading, 11, 3-32.

Wagner, R. K., \& Torgesen, J. K. (1987). The nature of phonological processing and its causal role in the acquisition of reading skills. Psychological Bulletin, 101, 192-212.

Wagner, R., Torgesen, J. K., \& Rashotte, C. A. (1999). Comprehensive Tests of Phonological Processing (CTOPP). Austin, TX: ProEd.

Watson, C., \& Willows, D. M. (1995). Information processing patterns in specific reading disability. Journal of Learning Disabilities, 28, 216-231.

Wechsler, D. (1991). Wechsler Intelligence Scale for ChildrenThird Edition (WISC-III). New York, NY: Psychological Corporation.

Wilkinson, G. S. (1993). The Wide Range Achievement Test 3. San Antonio, TX: Harcourt Assessment.

Wimmer, H., Mayringer, H., \& Landerl, K. (1998). Poor reading: A deficit in skill-automatization or a phonological deficit? Scientific Studies of Reading, 2, 321-340.

Wolf, M., Barzillai, M., Gottwald, S., Miller, L., Spencer, K., Norton, E., Lovett, M. W., \& Morris, R. D. (2009). The RAVEO intervention: Connecting neuroscience to the classroom. Mind, Brain, and Education, 3, 84-93.

Wolf, M., Bowers, P. G., \& Biddle, K. (2000). Naming speed processes, timing and reading: A conceptual review. Journal of Learning Disabilities, 33, 387-407.

Wolf, M., Goldberg-O'Rourke, A., Gidney, C., Lovett, M., Cirino, P., \& Morris, R. (2002). The second deficit: An investigation of the independence of phonological and naming-speed deficits in developmental dyslexia. Reading and Writing: An Interdisciplinary Journal, 15, 43-72. 
Wolf, M., Miller, L., \& Donnelly, K. (2000). Retrieval, Automaticity, Vocabulary Elaboration, Orthography (RAVE-O): A comprehensive, fluency-based reading intervention program. Journal of Learning Disabilities, 33, 375-386.

Woodcock, R. W. (1987). Woodcock Reading Mastery TestsRevised (WRMT-R). Circle Pines, MN: American Guidance Service.

\section{About the Authors}

Jan C. Frijtersis an Associate Professor at Brock University, Departments of Child and Youth Studies and Psychology. His primary research areas are modeling treatment outcomes, the role of motivation in reading disability and reading interventions, and the development of motivation for reading throughout childhood.

Maureen W. Lovett is a Senior Scientist in the Neurosciences and Mental Health Program at The Hospital for Sick Children, a Professor of Pediatrics, Medical Sciences, and Human Development and Applied Psychology at the University of Toronto. She is Founder and Director of the hospital's Learning Disabilities Research Program, a clinical research unit that develops and evaluates interventions for developmental reading disabilities. Her research focuses on questions about the effective remediation of decoding, word identification, fluency, and reading comprehension deficits in struggling readers of elementary, middle, and high school age.

Karen A. Steinbach is Clinical Research Project Manager of the Learning Disabilities Research Program at The Hospital for Sick
Children. Ms. Steinbach has overseen the implementation of several large multi-site grant funded studies. She supervises and trains psychology staff, and coordinates and directs all assessment and programming offered in our elementary-level research classrooms.

Maryanne Wolf is the John DiBiaggio Professor of Citizenship and Public Service, Director of the Center for Reading and Language Research, and Professor in the Eliot-Pearson Department of Child Development at Tufts University. Her recent research interests include reading intervention, early prediction, fluency and naming speed, cross-linguistic studies of reading, the relationship between entrepreneurial talents and dyslexia, and the uses of brain imaging in understanding dyslexia and treatment changes.

Rose A. Sevcik is Professor of Psychology at Georgia State University, Atlanta. Her research has focused on the language, communication, and reading acquisition of children and youth with developmental disabilities.

Robin D. Morris is the Vice President for Research and Regents Professor of Psychology at Georgia State University. He also holds a joint appointment in the Department of Educational Psychology and Special Education in the College of Education. His current research is focused on reading and language development, reading disabilities and dyslexia, bilingual language and reading development, and neuroimaging of the developing brain. 